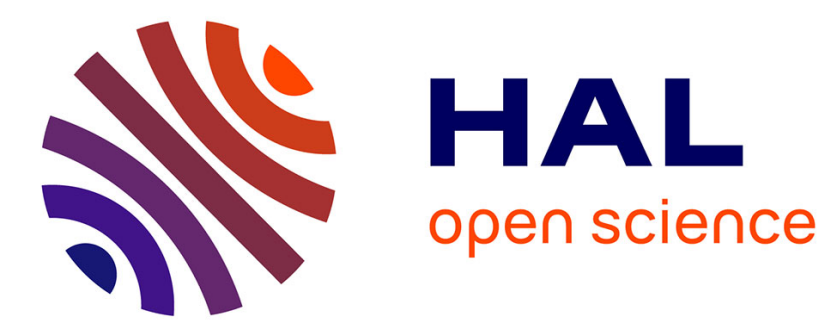

\title{
Performance of current eco-routing methods
}

Matěj Kubička, Jan Klusáček, Antonio Sciarretta, Arben Cela, Hugues

Mounier, Laurent Thibault, Silviu-Iulian Niculescu

\section{To cite this version:}

Matěj Kubička, Jan Klusáček, Antonio Sciarretta, Arben Cela, Hugues Mounier, et al.. Performance of current eco-routing methods. Intelligent Vehicles Symposium 2016, Jun 2016, Gothenburg, Sweden. 10.1109/ivs.2016.7535428 . hal-01318678

\section{HAL Id: hal-01318678 \\ https://hal.science/hal-01318678}

Submitted on 19 May 2016

HAL is a multi-disciplinary open access archive for the deposit and dissemination of scientific research documents, whether they are published or not. The documents may come from teaching and research institutions in France or abroad, or from public or private research centers.
L'archive ouverte pluridisciplinaire HAL, est destinée au dépôt et à la diffusion de documents scientifiques de niveau recherche, publiés ou non, émanant des établissements d'enseignement et de recherche français ou étrangers, des laboratoires publics ou privés. 


\title{
Performance of current eco-routing methods
}

\author{
Matěj Kubička, Jan Klusáček, Antonio Sciarretta, Arben Cela, Hugues Mounier \\ Laurent Thibault and S. I. Niculescu
}

\begin{abstract}
Eco-routing is a vehicle navigation method that aims to minimize fuel or energy consumption for a given trip. It is based on a hypothesis that we can trade extra travel time for lower consumption. While the hypothesis was experimentally verified the design of a method that would fully exploit its potential proves challenging. Current solutions hinge on assumption that energy spent on any given road does not change in time. We challenge validity of this assumption by studying performance of such methods in detailed second-bysecond simulation that pronounces the time-dependencies. This allows us to quantify the real savings attainable with current eco-routing.
\end{abstract}

\section{INTRODUCTION}

Eco-routing ${ }^{1}$ emerged as one of the strategies that aim to lower vehicle operating costs [12], [6], [4], [2]. The idea is to minimize energy (or fuel) consumption by route selection: given some origin and destination, eco-routing plots a route such that energy (fuel) needed to finish the trip is minimal.

The routing is usually done on a graph where nodes represent junctions, edges represent roads and costs are estimated energies needed to travel between two junctions the road connects. Minimal path routing ${ }^{2}$ can then be used to find the route that minimizes total energy for the trip. Authors typically reduce the complex time-variant functions that describe the costs. They must be time-invariant and nonnegative in order to use Dijkstra's routing algorithm, which is a common choice between authors.

Validation is often done using the same assumptions. Full experimental validation would require a host of identical vehicles to depart from spatially and temporally identical place in order to measure consumptions on different paths to destination reliably. This is difficult to realize in practice. Consequently, authors estimate performance of their methods

Matěj Kubička, Hugues Mounier and S. I. Niculescu are with L2S-CentraleSupelec, CNRS UMR8506, Univ. Paris-Sud, 91192, Gif-SurYvettes Cedex, France. matej.kubickallss.supelec.fr, hugues.mounieralss.supelec.fr,

silviu.niculescullss.supelec.fr.

Arben Cela is with UPE, ESIEE Paris, 93162, Noisy-Le-Grand Cedex, France, arben.celadesiee.fr

Jan Klusáček is with Brno University of Technology, The Faculty of Electrical Engineering and Communication, Department of Control and Instrumentation; Technická 3082/12, 61600, Brno, Czech Republic xklusa00@stud. feec.vutbr.cz

Antonio Sciarretta and Laurent Thibault are with IFP Energies Nouvelles, 1\&4, avenue de Bois-Préau, 92852 RueilMalmaison, France. antonio.sciarrettadifpen.fr, laurent.thibaulteifpen.fr

${ }^{1}$ Note that the term "eco-routing" is also used in a context of emissions minimization; we do not consider emissions in this study.

${ }^{2}$ Commonly also known as shortest path routing; we don't use this term to avoid confusion with routing that minimizes travel distance. by comparing estimated consumption of the eco-routes to estimated consumption of the shortest routes. In other words, the same model with the same assumptions is used for both routing and validation. We validate eco-routing methods without the time-invariancy assumption and with consumption models experimentally validated on real vehicles. This allows us to reason about ability of eco-routing to lower the consumption. Three eco-routing methods are studied in this way. Their performance is evaluated for both electric and conventional vehicles. We chose to make distinction between the two because the electric vehicle can recuperate braking energy. This has fundamental effect on consumption.

The original study that considered the idea of eco-routing is by Ericsson et al. [10]. Authors tried to estimate the potential of eco-routing based on route choices of real drivers. They used a collection of 15437 recorded commutes to compute typical consumptions on streets of Lund, Sweden. Then, they looked at 109 real journeys and estimated how many of them could be optimized and what is the expected gain for those that could be. They conclude that fuelefficiency could be enhanced for $46 \%$ of the trips and that fuel savings would be $8.2 \%$ on the average.

A study similar to ours is by Richter et al. [16]. Authors study the potential of eco-routing in a simulation of inner city traffic. They used simulation tool ULTraSim [15] to compute average consumption on every road in their map for electric, plugin hybrid and conventional vehicles. Then, they chose thirteen origin-destination pairs and plotted the shortest route and the eco-route for each. Reported fuel savings were $8.5 \%$ on the average for eco-route against the shortest route. This is similar to the findings of Ericsson et al.

A field study of the impact of route choice on the consumption and emissions was conducted by Ahn and Rakha [2]. Authors recorded thirty-nine trips over two routes during morning commute. These trips shared the same origin and destination, but eighteen of them took the arterial route and twenty-one the highway. These two roads are reported to have different speed limits and different commute patterns. Authors observe that fuel consumption is lower by $4-8 \%$ when taking the slower arterial route.

Another field study similar to the one by Ahn and Rakha was conducted by Minett et al. [14]. Authors recorded forty trips between the cities Delft and Zoetermeer taking either motorway, local or provincial road. They report consumption on local road lower by $17 \%$ with respect to the motorway.

Our study is most similar to the approach of Richter et al. [16] and Ericsson et al. [10]. Our contribution with respect to these works is multifold: 
- We compare eco-routes to the shortest and to the fastest routes. The idea of eco-routing is to trade extra travel time for lower consumption, hence it makes more sense to draw conclusions with respect to the fastest routes rather than the shortest ones.

- We simulate every route (eco-route, shortest route, fastest route) separately and ensure that the initial conditions are identical for each (same departure time, same traffic state) to sustain comparability.

- We ran our simulations on a large set of randomized trip origins and destinations. This allows us to sample the probability distribution of energy savings.

The paper is organized as follows: section II below defines eco-routing, section III reviews tested eco-routing methods and section IV presents the design of our experiment. Then, our findings are shown in section $\mathrm{V}$ and discussed in section VI. Conclusions are presented in section VII.

\section{PROBLEM STATEMENT}

Let $G=(V, E)$ be a road network graph, where $V=$ $\left\{n_{k}: k=1 \ldots M\right\}$ is a set of nodes with cardinality $M$ and $E=\left\{e_{k}: k=1 \ldots N\right\}$ is a set of arcs with cardinality $N$. The nodes represent roads between two junctions, arcs describe the connections between them. We refer to $G$ simply as map.

Lets assume we know cost function $f: V \rightarrow \mathbb{R}$ (abbrev. $f_{k}$ for $k$-th node in $V$ ) that describe how much energy is needed to travel between the two junctions the road connects. Let $p$ be a path (also called a route) defined as a contiguous sequence of nodes $p=\left\{n_{o}, \ldots, n_{d}\right\}$, where $n_{o}$ and $n_{d}$ are the origin and destination nodes. We distinguish three types of paths: the shortest path $p_{s}$, the fastest path $p_{f}$, and the eco-route $p_{e}$. The energy consumption of a path is a sum of energies lost at each node, hence

$$
E(p)=\sum_{k \in p} f_{k}
$$

We distinguish the energy of the eco-route, $E_{e}=E\left(p_{e}\right)$, the energy of the shortest route, $E_{s}=E\left(p_{s}\right)$, and the energy of the fastest route, $E_{f}=E\left(p_{f}\right)$. The eco-routing is defined as optimization problem

$$
\begin{aligned}
& p_{e}(o, d)=\underset{p \in \mathcal{P}}{\operatorname{argmin}} E(p) \\
& \text { s.t. } n_{1}=o \\
& n_{|p|}=d
\end{aligned}
$$

where $\mathcal{P}$ is the set of all simple paths in the map $G, n_{i}$ is $i$-th node in the path $p$ and $|p|$ is cardinality of the path $p$. The shortest path and the fastest path routing can be defined analogously such that the shortest path routing minimizes the distance and the fastest path routing minimizes the travel time.

\section{METhODS UNDER TEST}

This study was conducted on three well-known eco-routing methods, all of them conform to the model (2). First method is by Barth et al., originally proposed in [4] and further
TABLE I:

COEFFICIENTS FOR ECO-ROUTING

\begin{tabular}{rcrr} 
& F-City & Renault Scénic \\
\hline & $a$ & $113.5 \mathrm{~N}$ & $110.45 \mathrm{~N}$ \\
& $b$ & $0.774 \mathrm{~N} /(\mathrm{m} / \mathrm{s})$ & $1.5175 \mathrm{~N} /(\mathrm{m} / \mathrm{s})$ \\
Juřík et al. [12] & $c$ & $0.4212 \mathrm{~N} /(\mathrm{m} / \mathrm{s})^{2}$ & $0.5119 \mathrm{~N} /(\mathrm{m} / \mathrm{s})^{2}$ \\
& $M$ & $1,190 \mathrm{~kg}$ & $1,588 \mathrm{~kg}$ \\
& $\alpha$ & 0.85 & 0.0 \\
\hline & $\beta_{0}$ & -0.7123 & 0.9580 \\
& $\beta_{1}$ & $-2.2703 \cdot 10^{-2}$ & $-6.3418 \cdot 10^{-2}$ \\
Barth et al. [4] & $\beta_{2}$ & $-3.2109 \cdot 10^{-3}$ & $-1.1529 \cdot 10^{-3}$ \\
& $\beta_{3}$ & $1.0617 \cdot 10^{-4}$ & $7.0035 \cdot 10^{-5}$ \\
& $\beta_{4}$ & $-5.8308 \cdot 10^{-7}$ & $-4.1114 \cdot 10^{-7}$ \\
& $\beta_{5}$ & 2.3320 & 1.6148
\end{tabular}

extended in [6]. This is the first published eco-routing method we know of. Authors use a model called CMEM to estimate both fuel consumption and emissions. The CMEM is microscopic emissions and fuel intake model validated in [5]. The consumption on each road is approximated using

$$
\ln \left(f_{k}\right)=\beta_{0}+\beta_{1} v_{k}+\beta_{2} v_{k}^{2}+\beta_{3} v_{k}^{3}+\beta_{4} v_{k}^{4}+\beta_{5} s_{k}
$$

where $v_{k}$ is the average traffic speed and $s_{k}$ is the road grade. Authors obtained the $\beta$-coefficients using multivariate nonlinear regression on previously collected speed profiles. Average speed is sourced in real-time from a traffic information system.

Second method is by Andersen et al. [3]. Authors posses large amount of recorded trips in Denmark. Their positioning data originate from the GPS receivers, consumption is read from the vehicle using an on-board diagnostics interface. The routing is done on a road network of Denmark. Their function $f_{k}$ assigns each road the average consumption observed there. This method is interesting due to its simplicity. However, we believe authors are mixing different vehicle types in the same average which must lead to confounding since some vehicles show notoriously higher consumption than the others.

Third method is by Juřík et al. [12]. This method is based on physical consumption modeling: authors adapt the longitudal vehicle model [11] to estimate the consumption. They consider losses incurred by altitude changes, frictious losses and aerodynamic drag. Powertrain efficiency and heating in friction brakes is neglected. Their model reads

$$
f_{k}= \begin{cases}E_{r}+(\alpha-1) E_{p} & \text { if } E_{p} \leq 0 \\ E_{r} & \text { if } E_{p}>0\end{cases}
$$

where $E_{r}$ represents rolling friction and aerodynamic losses, $E_{p}$ is a potential energy and $\alpha$ is a constant representing recuperation capability of the vehicle. The $E_{r}$ and $E_{p}$ is given as

$$
\begin{gathered}
E_{r}=\frac{\rho}{2} A_{f} C_{d} v_{k}^{2} l_{k}+M g \mu_{r} l_{k} \cos \left(\theta_{k}\right) \\
E_{p}=M g \mu_{r} l_{k} \sin \left(\theta_{k}\right)
\end{gathered}
$$

where $v_{k}$ is the average speed and $l_{k}$ is the road length on the road $k$. Constants $\rho, A_{f}, C_{d}, M, \mu_{r}$ are vehicle-specific and $g$ is the gravitational constant. 


\section{Methodology}

Our experiments were conducted within a traffic simulation of real European city. The simulator allows us to introduce a vehicle, to set its route and to observe its progress in time. We ran simulations with the vehicles on different routes to the same destination, each time under identical initial conditions (same departure time, same origin, same traffic state). This allows us to record vehicle speed profiles which is essential when computing realistic estimates of consumption.

The departure time was set to midnight. The traffic is minimal at this time, hence perturbances due to the traffic are minimal. While it would be interesting to study eco-routing in congested urban settings this should come only after it was shown that eco-routing can perform in less perturbed environment.

We used two vehicle models: a model of FAM F-City electric vehicle and a model of conventional Renault Scénic. They are both standard consumption models based on onedimensional longitudal dynamics and powertrain efficiency maps with experimentally identified coefficients. The FCity model was validated in [9]. Authors observed 1.7\% consumption error during the test drive. We define the vehicle model as a function $\rho(v, a, s): \mathbb{R}^{n} \times \mathbb{R}^{n} \times \mathbb{R}^{n} \rightarrow \mathbb{R}$ that maps speed, acceleration and slope profiles of length $n$ to energy consumption. The speed profiles were extracted from the simulations, accelerations are based on difference quotients of the speed and the slope profiles come from digital elevation model of Europe [1]. It covers European continent with grid cell size of $25 \times 25$ meters. Bicubic interpolation was used to interpolate the terrain.

The simulation was conducted in a tool called SUMO [8] and on a scenario of Luxembourg developed and validated by Codecà et al. [7]. The scenario is based upon a map of Luxembourg, with synthetic traffic matched to Luxembourg's own traffic patterns. It features 286,884 vehicles over twenty-four hours on 931.12 kilometers of residential, arterial and highway roads. It has roundabouts, traffic lights, multi-lane roads and other features characteristic for urban traffic.

The toolchain used to conduct our experiment is on Figure 1. First we built a set of origin-destination pairs. For that we reused scenario's own trip origins and destinations as they are generated from real traffic demand in the Luxembourg city. This yielded 108, 356 origin-destinations pairs. We plotted eight routes between each origin and destination: three ecoroutes according to Barth et al., Juřík et al. and Andersen et al. for both electric and conventional vehicles plus shortest and fastest routes for reference. The routing was done upon a map $G=(V, E)$ extracted from the Luxembourg scenario. The shortest routes were routed using the cost function $f_{k}=l_{k}$, the fastest routes were routed using the cost function $f_{k}=\frac{l_{k}}{v_{k}}$. Note that the "fastest" route is an approximation of the real fastest route based on the average travel speeds. We resolved to this solution as computing the real fastest routes is a hard problem. The routing produced 866,848

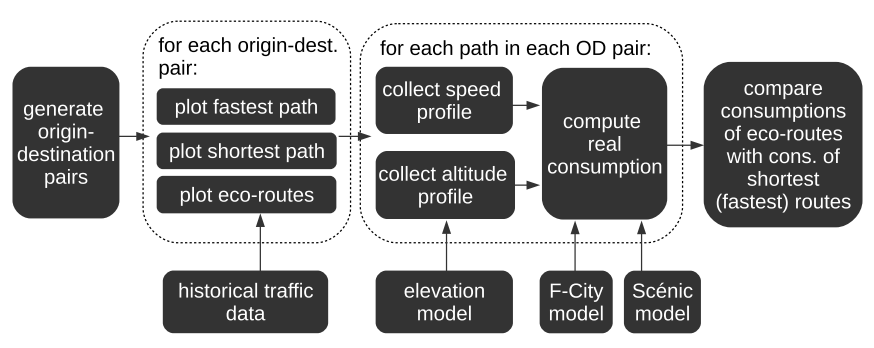

Fig. 1: Experiment toolchain (simplified)

routes in the map of Luxembourg. We simulated each route in the SUMO simulator, collected their speed profiles and computed their consumption using the reference models of Renault Scénic and FAM F-City. This required an equivalent of 559 hours of single core computing time on 96-core computing cluster. We have excluded data from 4781 origindestination pairs as they failed validity checks. While it is likely that the samples were in fact correct we prefer to remove samples for which we cannot be certain of their validity.

Methods by Juřík et al. and Barth et al. require real-time information about the average speeds in the network. Furthermore, Barth et al. and Andersen et al. require historically observed consumptions on the roads. We extracted necessary data beforehand from scenario's native traffic. Lets denote speed profile of $i$-th vehicle when traveling on road $k$ as $v_{k}^{(i)}$. The speed profile is a time series made of speeds measured at different time instants. For every vehicle, the consumption $f_{k}^{(i)}=\rho\left(v_{k}^{(i)}, \dot{v}_{k}^{(i)}, s_{k}\right)$ and the average speed denoted ${\overline{v_{k}}}^{(i)}$ is stored for each pass on each road in a quadruple $\left(f_{k}^{(i)}, \bar{v}_{k}^{(i)}\right.$, $s_{k}, l_{k}$ ) together with the road slope and road length. We have collected a total of 22,592,081 of these quadruples, 316 were removed due to failed sanity checks.

\section{A. Eco-routing implementation details}

Consumption estimates according to Barth et al. [4] are based on equation (3). We needed to compute the $\beta$ coefficients specific to our vehicles. For that reason we replaced the original vehicle model with our own and collected the quadruples $\left(f_{k}^{(i)}, \bar{v}_{k}^{(i)}, s_{k}, l_{k}\right)$ as discussed above. This provided necessary data to fit the $\beta$-coefficients using regression. Note that we had convergence problems when performing nonlinear regression on (3), instead we obtained the $\beta$-coefficients by regression on linearized model. See Table I for the results.

The method by Andersen et al. can suffer with a lack of observations in back alleys and other scarcely used roads. We used $f_{k}=\infty$ on roads on which we had no historical data (that is, when $m=0$ ). On the roads where we had the data we took their average. Hence,

$$
f_{k}= \begin{cases}\frac{1}{m} \sum_{i=1}^{m} f_{k}^{(i)} & \text { if } m>0 \\ \infty & \text { if } m=0\end{cases}
$$

Original proposal by Andersen et al. does not account for vehicle type. It follows that their averages are likely 
TABLE II:

CONSUMPTION ESTIMATION RESULTS

\begin{tabular}{lc|cc} 
& & F-City & Scénic \\
\hline \multirow{3}{*}{ Correlation } & Andersen & 0.987 & 0.989 \\
& Barth & 0.956 & 0.957 \\
& Juřík & 0.916 & 0.826 \\
\hline \multirow{3}{*}{ Std. error } & Andersen & $96 \mathrm{Wh}$ & $339 \mathrm{Wh}$ \\
& Barth & $234 \mathrm{Wh}$ & $792 \mathrm{Wh}$ \\
& Juřík & $484 \mathrm{Wh}$ & $2,493 \mathrm{Wh}$
\end{tabular}

TABLE III:

\section{RESULTS SUMMARY}

\begin{tabular}{lc|cc|cc} 
& & \multicolumn{2}{c}{ fastest } & \multicolumn{2}{c}{ shortest } \\
& & F-City & Scénic & F-City & Scénic \\
\hline \multirow{2}{*}{ Average } & Andersen & $12.5 \%$ & $8.4 \%$ & $7.5 \%$ & $4 \%$ \\
savings & Barth & $2.6 \%$ & $2.8 \%$ & $-3.6 \%$ & $-2.1 \%$ \\
& Juřík & $3.5 \%$ & $-3.9 \%$ & $-1.8 \%$ & $-8.8 \%$ \\
\hline \multirow{2}{*}{ Estimated } & Andersen & $14.7 \%$ & $9.9 \%$ & $9.2 \%$ & $5.7 \%$ \\
savings & Barth & $1.4 \%$ & $1.5 \%$ & $2.4 \%$ & $2.5 \%$ \\
& Juřík & $17.8 \%$ & $18.5 \%$ & $4.4 \%$ & $6.8 \%$ \\
\hline \multirow{2}{*}{ Maximum } & Andersen & $60.7 \%$ & $58.6 \%$ & $51.4 \%$ & $40.2 \%$ \\
savings & Barth & $58.1 \%$ & $54.6 \%$ & $40.9 \%$ & $35.6 \%$ \\
& Juřík & $60.9 \%$ & $56.5 \%$ & $51.4 \%$ & $39.1 \%$ \\
\hline \multirow{2}{*}{ Probability } & Andersen & $6.9 \%$ & $8.4 \%$ & $8.4 \%$ & $9.6 \%$ \\
of failure & Barth & $5.1 \%$ & $4.5 \%$ & $13.3 \%$ & $14.1 \%$ \\
& Juřík & $31.7 \%$ & $48.1 \%$ & $37.1 \%$ & $54.7 \%$ \\
\hline Eco-route & Andersen & $8.7 \%$ & $13.3 \%$ & $12 \%$ & $17.5 \%$ \\
same as & Barth & $60.6 \%$ & $63.0 \%$ & $30.8 \%$ & $30.2 \%$ \\
reference & Juřík & $6.6 \%$ & $6.2 \%$ & $16.7 \%$ & $11.8 \%$ \\
\hline \multirow{2}{*}{ Median of } & Andersen & $4.7 \%$ & $0.2 \%$ & & \\
time delay & Barth & $0 \%$ & $0 \%$ & & \\
& Juřík & $18.0 \%$ & $16.5 \%$ & & \\
\hline \multirow{2}{*}{$95^{\text {th }}$ perc. } & Andersen & $56 \%$ & $47.6 \%$ & & \\
time delay & Barth & $36.8 \%$ & $38.2 \%$ & & \\
& Juřík & $78 \%$ & $85.2 \%$ & & \\
& & & & &
\end{tabular}

compound from different vehicles with varying consumption characteristics. This necessarily leads to more uncertainty in estimated consumptions. We don't mix vehicle types in this study since we have only two vehicles. Instead, we use costs $f_{k}$ specific either for the electric vehicle or for the conventional vehicle. This is idealized with respect to the original.

We also adapted the consumption model of Juřík et al. as our vehicle description did not match the one used by the authors. Equation (5) was changed to

$$
E_{r}=\left(c v_{k}^{2}+b v_{k}+a\right) l_{k}
$$

where $a, b$ and $c$ are coast-down parameters: coefficients of polynomial fitted to experimentally measured relation between the force acting against vehicle movement and the speed. From modeling point of view this has comparable meaning to the original approach, however, it neglects dependence of rolling losses on road grade. For the values see Table I.

\section{RESUlts}

The results presented in this section are based on a collection of 828,600 simulated routes between 103,575 unique origin-destination pairs. Raw experiment data is available online [13], our findings are summarized below.
Correlations of consumption estimates according to Barth et al., Juřík et al. and Andersen et al. with the reference consumptions are shown on Figure 2. Results for the electric vehicle are on Figure 2a and for the conventional vehicle on Figure 2b. Each sample represents a single trip. Perfect estimation would be achieved along the black line. Pearson's product-moment correlation coefficients and standard errors are listed in Table II.

Probability distributions of relative consumptions are shown on figures 3 and 4 . Former shows consumption of the eco-routes relative to the fastest routes (ratio $E_{e} / E_{f}$ ), latter relative to the shortest routes (ratio $E_{e} / E_{s}$ ). There are three curves in each plot, one for each method. We observed exceptionally high probability of the eco-route being identical to the shortest (resp. fastest) route. Since the distributions have discontinuity at this point we removed it from the plots and report probabilities at this particular point in Table III where we summarize the results. The Table III has following sections

1) "Average savings" and "Estimated savings" list the average of actually saved energy and the average of a priori estimates of saved energy. Former tells how much was actually saved while latter tells how much was expected to be saved.

2) "Probability of failure" gives sample probability that the eco-route is less economic than the fastest (resp. shortest) route and that it requires longer travel time than the fastest (resp. shortest) route.

3) "Eco-route same as reference" gives sample probability that eco-route is identical to the fastest (resp. shortest) route.

4) "Median of time-delay" and "95-th percentile time delay" are statistics of travel time delays. They have heavy-tailed distributions so we report the median rather than the mean to give a robust estimate of central tendency.

Sampled eco-route consumptions do not come from the same population as the shortest and fastest routes. We reject the hypothesis that any of the six measured eco-route consumption sample sets (three eco-routing methods for two distinct vehicle types) come from the same population as the samples of the shortest or the fastest route consumption. We tested the hypothesis using Mann-Whitney U test. In the total of twelve tests the largest two-sided $p$-value was smaller than $10^{-7}$, hence the differences are statistically significant on $99 \%$ level. We used the $\mathrm{U}$ test rather than the t-test because the t-test assumes the population distribution is normal. The d'Agostino's normality test on the sampled distributions returns high $\chi^{2}$ statistic for all sample sets. Corresponding $p$-values are smaller than $10^{-10}$ for the hypothesis that the consumption distributions are normal, hence we adapted the alternative hypothesis.

\section{DISCUSSION}

The method by Andersen et al. shows highest correlation of consumption estimates with the reference and the standard estimation error of $96 \mathrm{Wh}$ for the electric vehicle is lowest 


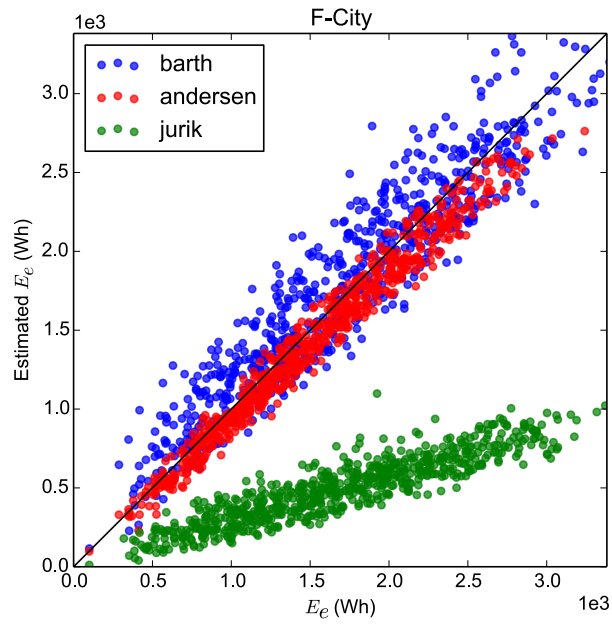

(a) electric vehicle

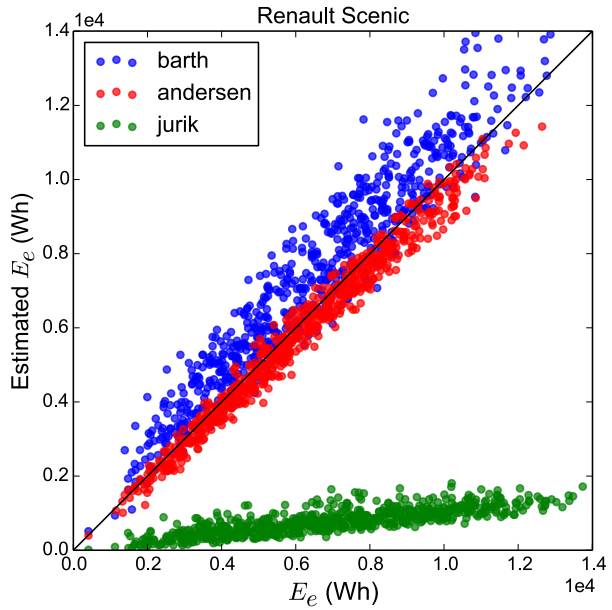

(b) conventional vehicle

Fig. 2: Correlations of estimated and reference consumptions

between the competing methods. However, the estimation can't be expected to work so well in practice. As discussed in section IV-A we used vehicle-specific consumption averages while the original method mixes consumptions from different vehicle types into a single average. Quality of the consumption estimates reflects on eco-routing performance: Andersen et al. achieves the highest average savings (up to $12.5 \%$ ) and low probability of failure (ranging from $6 \%$ to $10 \%)$.

The consumption estimates by Barth et al. show more spread than estimates by Andersen et al. (see Figure 2) but still retain high correlation ( 0.95 for both vehicles). Standard errors are roughly tripled with respect to Andersen et al.. Routing performance shows average savings close to $2.5 \%$ for both vehicles when compared to the fastest route. When compared to the shortest route the average savings drop to negative values. According to this result we are more likely to save energy if we drive along the shortest route, rather than along the eco-route.

The method by Juř́k et al. underestimates consumption severely, as can be seen on Figure 2. This is by design as au-

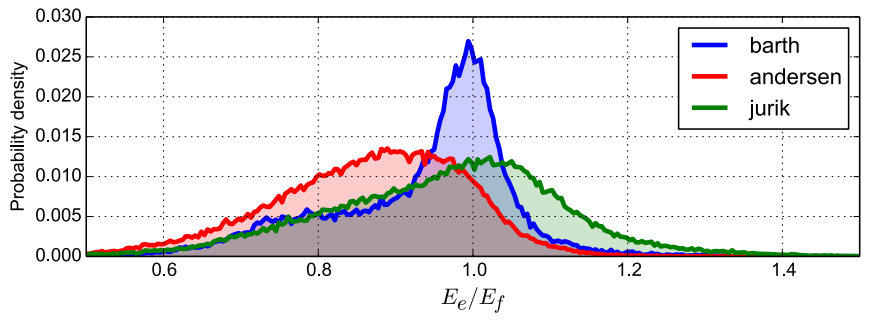

(a) electric vehicle

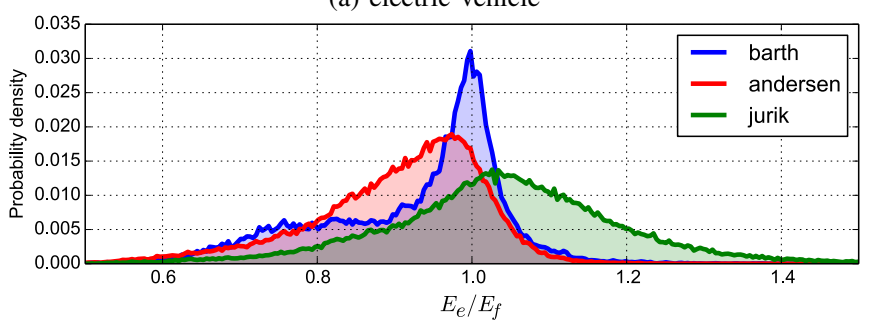

(b) conventional vehicle

Fig. 3: Sample distribution of energy savings relative to fastest routes

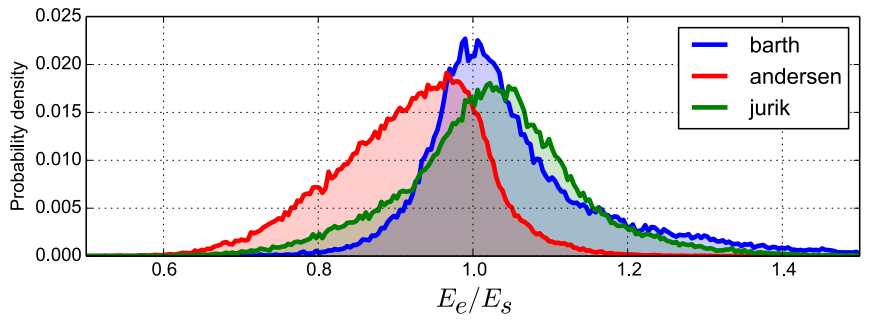

(a) electric vehicle

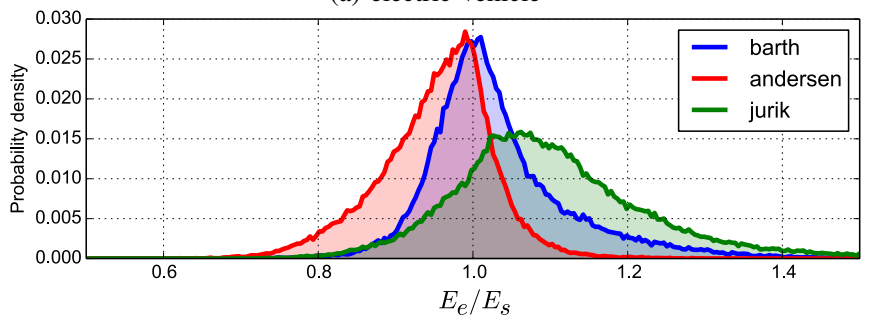

(b) conventional vehicle

Fig. 4: Sample distribution of energy savings relative to shortest routes

thors neglect powertrain efficiency. They observed that scale error will not affect correlation, nor eco-routing performance. Indeed, structure of the shortest paths in a graph where all the costs are scaled by the same positive amount will not be altered. Consumption correlation is 0.92 for the electric vehicle and 0.83 for the conventional vehicle. Standard errors are roughly six times higher than those of Andersen et al. Routing performance is best for the electric vehicle, showing $3.5 \%$ savings with respect to the fastest route. However, ecoroute still performs worse than the shortest route on average. For the conventional vehicle we see worst performance among all: $-8.8 \%$ savings with respect to the shortest route. This is not surprising as Juřík et al. designed their method for electric and hybrid vehicles.

The method by Juřík et al. is most practical: it is based on a standard vehicle consumption model and the physical laws it 
entails. Hence, there is no need to utilize historical data, nor to fit any coefficients. Method by Barth et al. requires a set of prerecorded trips and Andersen et al. requires specialized hardware.

Juř́k et al. and Andersen et al. overestimate the expected savings. They must be, by definition, positive. However, we have seen that the real savings are often negative on the average. This cannot be accounted for as long as we assume that the consumption does not change in time. Unfortunately, this is also the assumption that makes the current eco-routing feasible.

Results are generally better for the electric vehicle. Even when correlation score is high for both electric and conventional vehicles the savings are higher for the electric vehicle. For example in the case of Andersen et al. the correlation is 0.99 for both, but the electric vehicle enjoys average savings of $12.5 \%$ while conventional vehicle only $8.4 \%$.

\section{CONCLUSION}

We have recreated three eco-routing methods published in the literature and tested them in simulated urban traffic to quantify their ability to lower the energy or fuel consumption needed to finish a trip. The three methods were chosen such that they make use of different ideas to achieve their task: Andersen et al. [3] simply averages observed energy consumptions, Barth et al. [4] uses regression model to estimate the consumption and Juřík et al. [12] uses a physical model of a vehicle to do the same. We cannot guarantee that our results are representative of reality. However, the simulations are matched to mobility patterns of a real city and highly detailed both in terms of temporal resolution and size. Moreover, our referential vehicle models are based upon real vehicles and standard modeling methodology.

The results support the eco-routing hypothesis: eco-routes can have a lower consumption than the fastest routes on the average as shown by methods of Barth et al. and Andersen et al. Among the three competing methods Andersen et al. have shown the best results ( $12.5 \%$ average savings), but we conjecture that this is not attainable in practice as we idealized the method. When we compare the eco-routes to the shortest routes we find that the methods by Juřík et al. and Barth et al. offered eco-routes that were less economic than the shortest routes. Eco-routes by Andersen et al. performed better, however, since the method was idealized it remains unanswered whether this will hold in practice. However, it shows that eco-routing has the potential to deliver interesting savings. In order to attain it we need better consumption estimates.

We observed that the eco-routes often fail to save energy. This is particularly problematic if the eco-route also requires longer time to destination. Then, the eco-routing advises us to take less economic route for a longer time. We formulated occurrences of this as "probability of failure" and observed that it happens between $5 \%$ and $55 \%$ of the time, depending on the method and used vehicle. This is to our best knowledge the first time the likelihood of failure was observed and further study to its causes is necessary. Indeed, no sensible user would accept $50 \%$ chance that eco-routing will navigate him on a path that is less economic and incurs travel time delays.

We provide open access to the dataset with experiment data [13]. It contains an XML file with all the routes, simulation results and consumptions. A script written in Python that generates the plots and tables shown here is attached to the dataset.

\section{REFERENCES}

[1] EU Digital Elevation Model. http://www.eea.europa.eu/ data-and-maps/data/eu-dem. Accessed: 2016-01-22.

[2] Kyoungho Ahn and Hesham Rakha. The effects of route choice decisions on vehicle energy consumption and emissions. Transportation Research Part D: Transport and Environment, 13(3):151-167, 2008.

[3] Olav Andersen, Christian S Jensen, Kristian Torp, and Bin Yang. Ecotour: reducing the environmental footprint of vehicles using ecoroutes. In Mobile Data Management (MDM), 2013 IEEE 14th International Conference on, volume 1, pages 338-340. IEEE, 2013.

[4] Matthew Barth, Kanok Boriboonsomsin, and Alex Vu. Environmentally-friendly navigation. In Intelligent Transportation Systems Conference, 2007. ITSC 2007. IEEE, pages 684-689. IEEE, 2007.

[5] Matthew Barth, Carrie Malcolm, Theodore Younglove, and Nicole Hill. Recent validation efforts for a comprehensive modal emissions model. Transportation Research Record: Journal of the Transportation Research Board, (1750):13-23, 2001.

[6] Kanok Boriboonsomsin, Matthew Barth, Weihua Zhu, and Alexander Vu. Eco-routing navigation system based on multisource historical and real-time traffic information. Intelligent Transportation Systems, IEEE Transactions on, 13(4):1694-1704, 2012.

[7] Lara Codecà, Raphaël Frank, and Thomas Engel. Luxembourg SUMO traffic (LuST) scenario: 24 hours of mobility for vehicular networking research. In Proceedings of the 7th IEEE Vehicular Networking Conference, pages 1-8, 2015.

[8] Krajzewicz Daniel, Jakob Erdmann, and Bieker Laura Behrisch, Michael and. Recent development and applications of SUMO Simulation of Urban MObility. International Journal On Advances in Systems and Measurements, 5(3\&4):128-138, December 2012.

[9] W. Dib, A. Chasse, D. Di Domenico, P. Moulin, and A. Sciarretta. Evaluation of the energy efficiency of a fleet of electric vehicle for ecodriving application. Oil \& Gas Science and Technology, 67(4):589$599,2012$.

[10] Eva Ericsson, Hanna Larsson, and Karin Brundell-Freij. Optimizing route choice for lowest fuel consumption-potential effects of a new driver support tool. Transportation Research Part C: Emerging Technologies, 14(6):369-383, 2006.

[11] Lino Guzzella and Antonio Sciarretta. Vehicle propulsion systems: introduction to modeling and optimization. Springer, 2005.

[12] Tomáš Juř́ik, Arben Cela, Redha Hamouche, Rene Natowicz, Abdellatif Reama, Silviu-Iulian Niculescu, and Jérôme Julien. Energy optimal real-time navigation system. Intelligent Transportation Systems Magazine, IEEE, 6(3):66-79, 2014.

[13] Kubička Matěj, Jan Klusáček, Antonio Sciarretta, Arben Cela, Hugues Mounier, Laurent Thibault, and S. I. Niculescu. Performance of current eco-routing methods - experiment data. http://dx.doi. org/10.5281/zenodo.50653, April 2016. DOI: 10.5281/zenodo. 50653 .

[14] Claire F Minett, Winnie Daamen, Bart Van Arem, Sjon Kuijpers, et al. Eco-routing: comparing the fuel consumption of different routes between an origin and destination using field test speed profiles and synthetic speed profiles. In Integrated and Sustainable Transportation System (FISTS), 2011 IEEE Forum on, pages 32-39. IEEE, 2011.

[15] Maximilian Richter, Thierauf D., and Herbert Kabza. ULTraSim, a traffic simulator incorporating submicroscopic BEV, HEV, ICEV models. EVS.

[16] Maximilian Richter, Sebastian Zinser, and Herbert Kabza. Comparison of eco and time efficient routing of ICEVs, BEVs and PHEVs in inner city traffic. In Vehicle Power and Propulsion Conference (VPPC), 2012 IEEE, pages 1165-1169. IEEE, 2012. 